\title{
DUPLICATION OF THE MITRAL VALVE
}

\author{
BY \\ E. D. WIGLE* \\ From the Department of Pathology, Postgraduate Medical School, Hammersmith
}

Duplication of the mitral valve is a rare congenital cardiac anomaly, only twenty instances having been previously reported. There are on record in addition two cases of triplication of the mitral valve, a condition presumably resulting from a similar defect in development. Duplication of the tricuspid valve also occurs, but less commonly than the mitral anomaly. This case is reported in order to draw attention to several interesting facets of the condition, namely, the embryology, the occasional presence of an apical diastolic murmur, and the association with certain other congenital cardiac anomalies.

\section{Case Report}

Present Illness. On August 10, 1955, a sixty-five-year-old single woman was admitted for the first time to Hammersmith Hospital with a history of having had attacks of winter bronchitis for the past twenty years, ankle œdema for eighteen months, and a severe attack of bronchitis six months previously. The latter was followed by progressive loss of weight, exertional dyspnœa, orthopnœa, and angina pectoris. For the three weeks prior to admission the patient noted extreme weakness and pleuritic pain on the right side of the chest.

Past History. The patient spent a normal active childhood, although she was told when very young that she had a damaged heart valve. Hysterectomy was performed for adenocarcinoma of the body of the uterus in 1948; the blood pressure was then 195/115. Between 1951 and 1954 she was operated on for partial thyroidectomy and intestinal obstruction. While in hospital she was found to have aortic and mitral valve disease.

Examination revealed a pale, febrile, seriously ill woman. The heart was enlarged to the left. There was an aortic systolic murmur and thrill, an apical mid-diastolic murmur, a loud pericardial friction rub, and evidence of moderately severe congestive cardiac failure. Blood pressure: 120/75. Investigation revealed a severe iron deficiency anæmia and occult blood in the stools. Serial electrocardiograms revealed right and left ventricular hypertrophy, pericarditis, and possible antero-septal ischæmia. Fluoroscopy of the chest showed enlargement of the left atrium, and of the left and right ventricles. A barium meal demonstrated a mass pressing on the greater curvature of the stomach. There was no laboratory or clinical evidence to suggest a diagnosis of myxœdema.

During the patient's stay in hospital the congestive heart failure responded well to digitalis and mercurial diuretics, but she remained febrile and very weak. Repeated blood transfusions corrected the anæmia and improved her general condition to some extent. On October 31 the patient developed severe pain in the left hypochondrium and a large craggy mass then became palpable in this region. Following this, her condition deteriorated gradually and two weeks later the abdomen became distended and the size of the mass in the left hypochondrium increased. Operation was considered, but the patient's general condition forbade this, and she died four days later.

\section{Post-mortem Examination (7403)}

This was performed 36 hours after death. In the lungs there was evidence of chronic bronchitis, bilateral pulmonary œdema, and basal bronchopneumonia, and congenital absence of the right middle lobe. There was a volvulus of the terminal portion of the ileum causing incomplete obstruction, resulting in dilatation

* During the tenure of a British Council Scholarship. 
of the small intestine proximally. The spleen was massively enlarged, measuring $28 \times 15 \times 15 \mathrm{~cm}$., all but the tip being replaced by necrotic tumour tissue (primary in uterus, 1948). The interval between removal of the primary site and the recurrence of secondaries was long (8 years), but not exceptionally so (Willis, 1952). One gland at the hilum of the spleen was also involved by tumour. There was a medullary fibroma of the right kidney.

Examination of the Heart and Great Vessels. There was coarctation of the aorta of adult type, the lumen at the point of narrowing measuring $15 \mathrm{~mm}$. in diameter. There was dilatation of the ascending aorta, aneurysmal dilatation of the proximal $3 \mathrm{~cm}$. of the left subclavian artery and a patch of atheroma on the medial wall of the aorta immediately distal to the coarctation. No evidence of collateral circulation was found. The heart weighed 499 grammes and the epicardial surface showed evidence of fibrineus jericiarüuitis. The left and right ventricles were hypertrophied, their outflow tracts measuring 21 and $5 \mathrm{~mm}$. in thickness respectively. There was also hypertrophy and slight dilatation of the left atrium. The aortic valve was bicuspid, the cusps being of equal size. The two coronary arteries, which were free of atheroma, arose from the two extremes of the anterior cusp. The cusp margins were thickened and rolled, but not appreciably retracted. The aortic orifice would admit the tip of an index finger. There was a calcified median raphe of the anterior cusp that did not extend to the free margin. Masses of calcium were present in the sinuses of Valsalva and on the ventricular surface of the posterior cusp. From the latter area a ridge of calcium extended down on the ventricular surface of the anterior mitral cusp to its free margin, limiting normal movement of this leaflet (Fig. 1). The mitral valve itself was duplicated (Fig. 1 and 2), the anterior and posterior orifices measuring 40 and $60 \mathrm{~mm}$. in circumference respectively. These orifices were separated by a bridge of fibrous tissue $9 \times 3 \mathrm{~mm}$. to which chordæ tendineæ were attached. This bridge appeared to be dividing what was otherwise a normal mitral valve. Each orifice had two cusps of

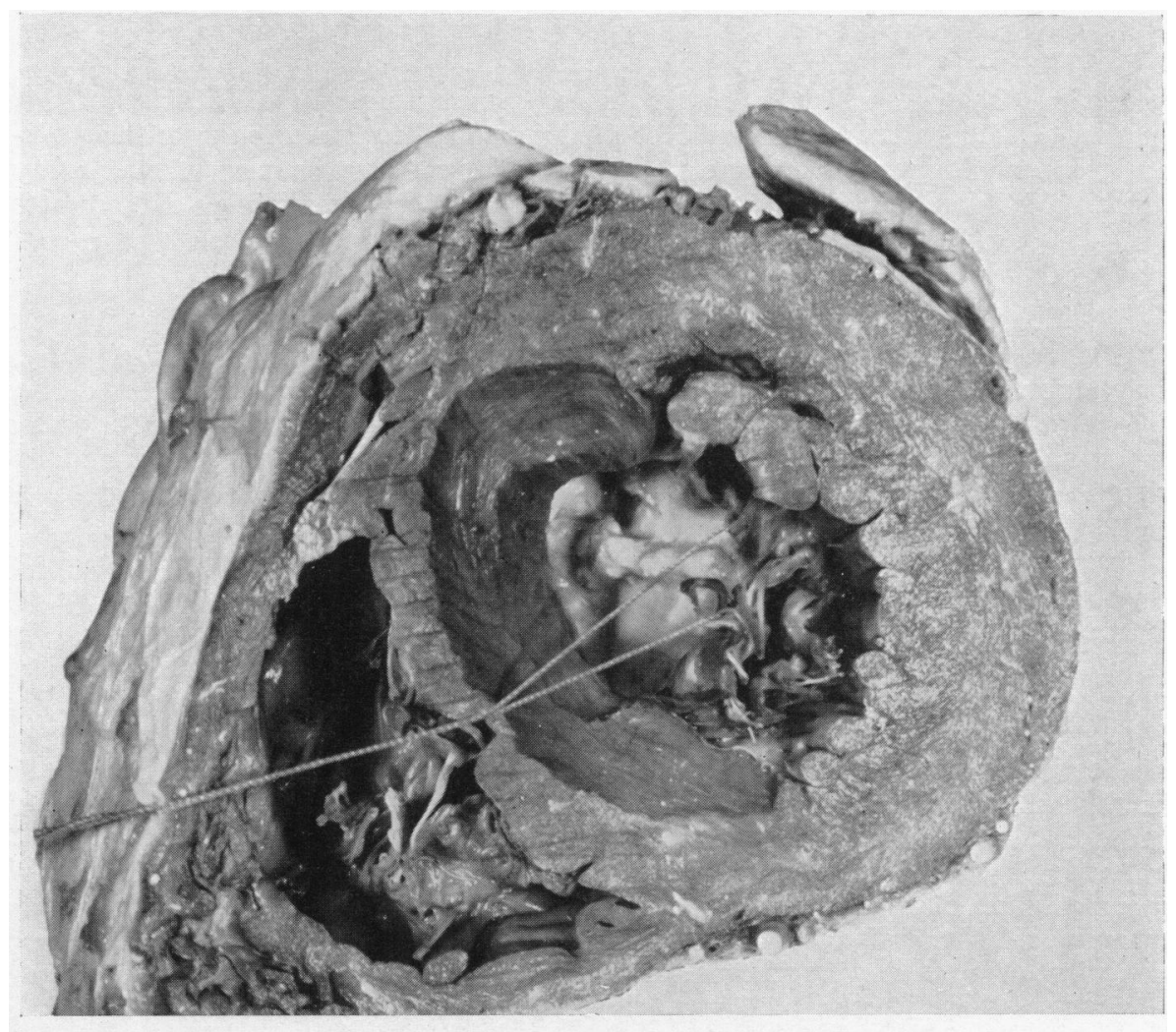

FIG. 1.-Duplication of the mitral valve viewed from the left ventricle. A piece of thread has been looped under the fibrous " bridge" to hold the valve cusps apart. Note the ridge of calcium extending down from the posterior cusp of the aortic valve. 


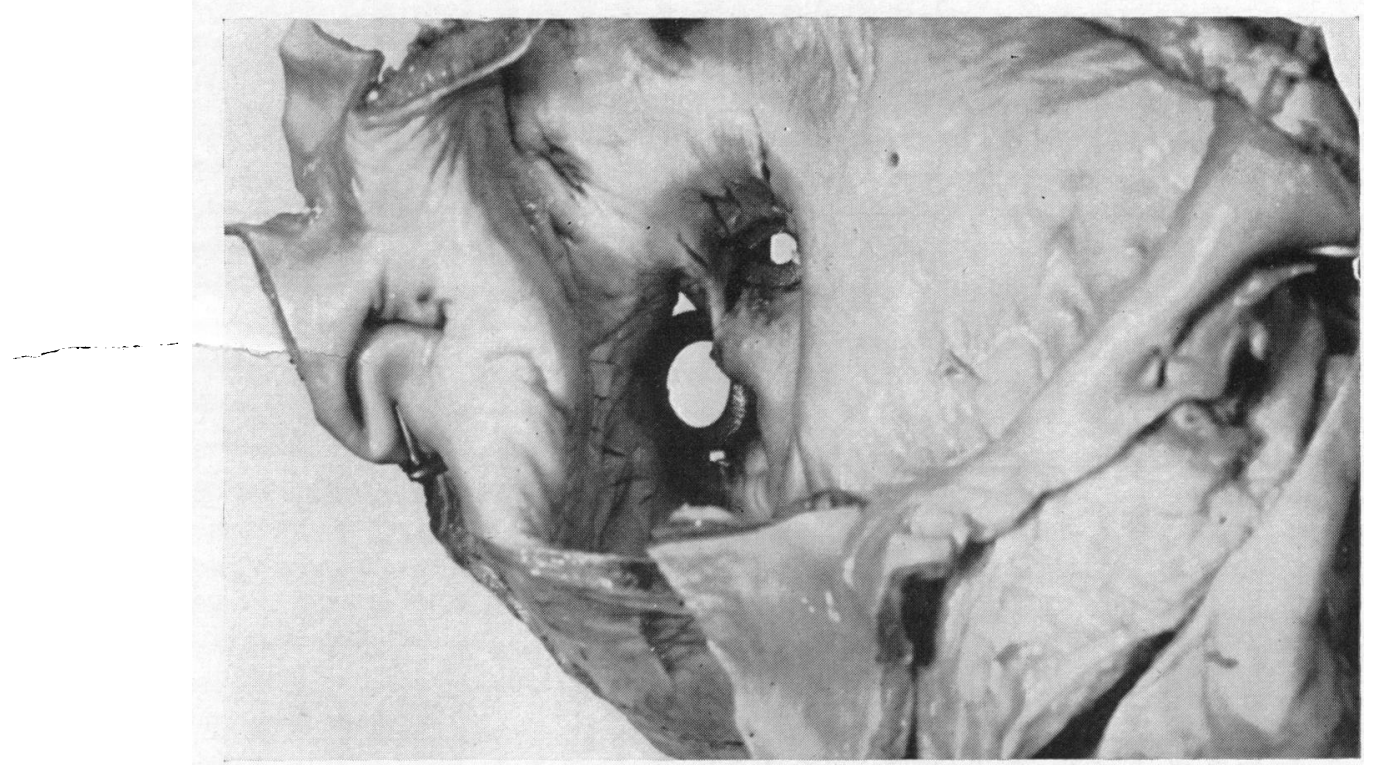

Fig. 2.-Duplication of the mitral valve viewed from the left atrium. Pieces of rubber have been inserted into the orifices of the formalinized specimen to hold them open. The smaller anterior orifice is slightly to the left of the posterior orifice.

normal appearance. The chordæ tendineæ to the cusps of the anterior orifice arose from a small group of papillary muscles high on the anterior wall of the left ventricle. The chordæ to the posterior orifice arose from a larger anterior papillary muscle and the posterior papillary muscle. No evidence of previous rheumatic disease was found either in the gross or in the microscopic examination of the heart.

\section{Discussion}

In eight of the twenty cases of duplication of the mitral valve hitherto reported, the two orifices were of equal size. Of the twelve cases with unequal sized orifices, the smaller " accessory" orifice was anterior in ten and posterior in two. In seven of the ten cases with a smaller anterior orifice, this orifice was described as being a hole in the anterior mitral cusp; in one of the two cases with a smaller posterior orifice, the accessory orifice was described as being a hole in the posterior cusp. In the remaining four cases with unequal orifices and in the eight cases with equal sized orifices, the authors described the valve as being divided by a "bridge" of fibrous tissue.

Sixteen of the cases were described as having two normal cusps for each orifice; in the remaining four cases the cusps of the smaller orifice were described as being rudimentary or absent. In ten of the twelve cases with adequate descriptions of the papillary muscles, the chordæ tendineæ from the anterior papillary muscle were attached to the cusps of the anterior orifice and the chordæ from the posterior papillary muscle were attached to the cusps of the posterior orifice. In Cohn's case (1897) and that of Davies and Fisher (1934), an anterior papillary muscle supplied chordæ to the anterior orifice and a second anterior papillary muscle plus the posterior papillary muscle supplied chordæ to the posterior orifice. Of the fourteen cases in which the sex of the subject was mentioned nine were male and five female.

In all but three cases the duplicated mitral valve was an incidental post-mortem finding. In the case described by Davies and Fisher, an apical mid-diastolic or presystolic murmur was heard from time to time over a number of years of observation. Their patient had in addition coarctation of the aorta and a bicuspid aortic valve. Matterstock's (1877) case had an apical diastolic murmur for the three days prior to death, the patient dying of a severe anæmia. The physician who discussed Paul's (1930) case stated that there was evidence of mitral stenosis and insufficiency, plus a diastolic murmur at the point of Erb; in this patient there was in addition subaortic stenosis, a bicuspid aortic valve, and a patent ductus arteriosus.

Associated congenital cardiac anomalies were noted in six of the twenty cases, the commonest of these being a bicuspid aortic valve (three cases) and a persistent ostium primum (three cases). 
Embryology. Though Camisa (1912) believed his two cases to be due to fœtal endocarditis, the developmental basis for duplication of the mitral valve now seems well established. Normally in early embryonic life, the ventral and dorsal endocardial cushions of the primitive atrio-ventricular canal fuse, thereby forming the left and right primitive atrio-ventricular openings (Fig. 3, I and II). The left segments of the fused ventral and dorsal endocardial cushions form the medial cushion of the mitral orifice and project into the left ventricle as the ventral and dorsal tubercles of that cushion. Subsequently the lateral mitral cushion is formed, and, by an undermining process, these cushions are converted into the medial (anterior) and lateral (posterior) mitral cusps.

In 1948 Wimsatt and Lewis described two different embryological theories to explain duplication of the mitral valve. Wimsatt believed, as did Hartmann (1937), that the anomaly was due to adhesion between the ventral or dorsal tubercles of the medial cushion with the lateral cushion (Fig. 3, III). Adhesion between the ventral tubercle and the lateral cushion would give rise to a smaller anterior orifice and adhesion between the dorsal tubercle and the lateral cushion would give rise to a smaller posterior orifice. Two orifices of equal size would result from fusion near the mid-point of each cushion. Wimsatt believed that with growth of the left ventricle the point of fusion would be subjected to tension and drawn out to form the bridge of fibrous tissue described in so many cases.

Lewis, on the other hand, believed that duplication of the mitral valve resulted from failure of complete
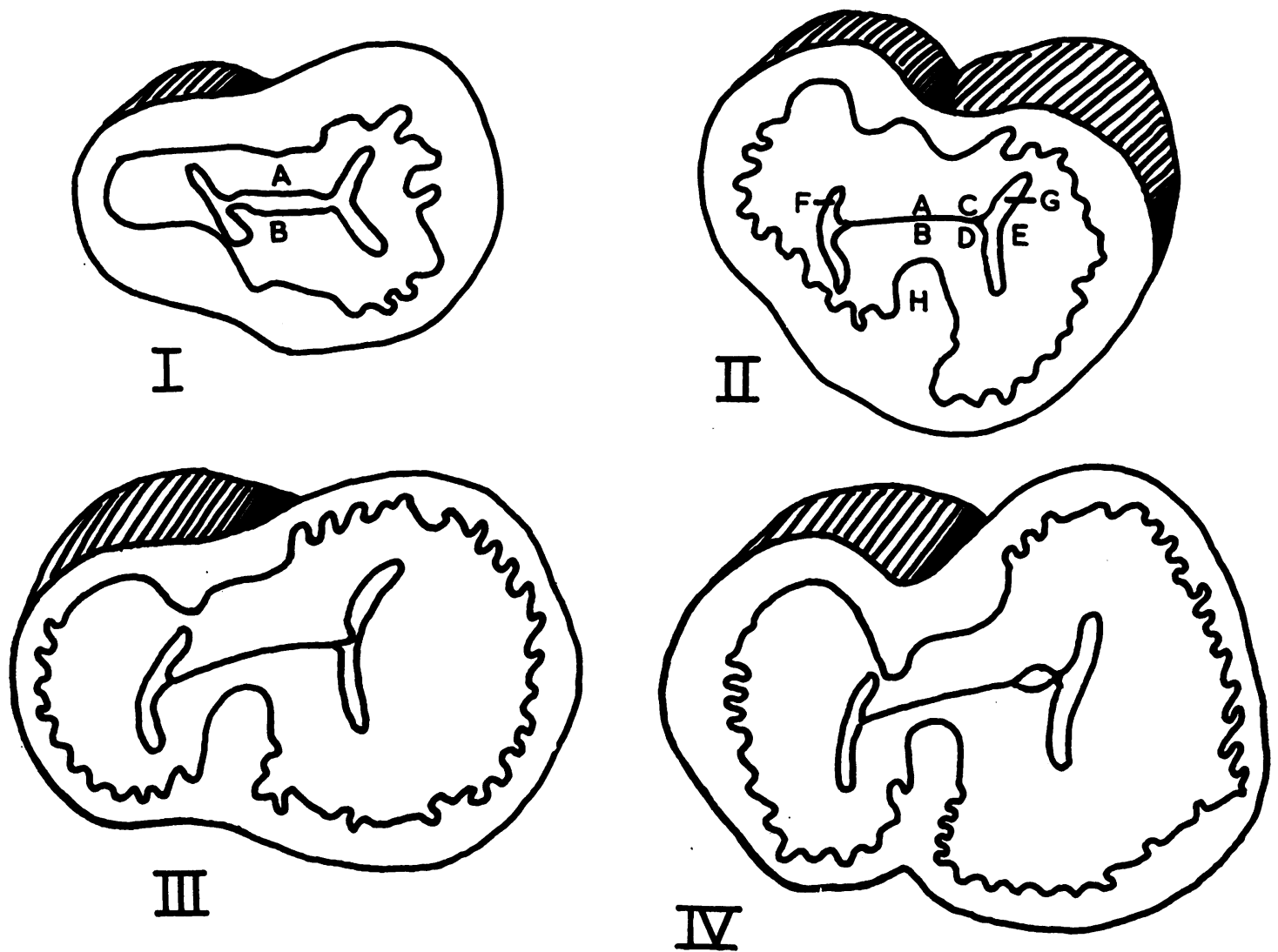

FIG. 3.-The diagrams represent embryonic hearts in which the apex has been cut off and the specimens viewed from below. I and II show the normal development of the mitral valve before, and after, fusion of the ventral and dorsal endocardial cushions. III shows the fusion of the ventral tubercle of the medial mitral cushion with the lateral cushion (Wimsatt). IV shows the failure of complete fusion of the left segments of the ventral and dorsal endocardial cushions (Lewis).

A, Ventral endocardial cushion; B, dorsal endocardial cushion; C, ventral tubercle of the medial cushion; D, dorsal tubercle of the medial cushion; E, lateral cushion; F, right A.V. orifice; G, left A.V. orifice; H, interventricular septum. 
fusion of the left segments of the ventral and dorsal endocardial cushions medial to the tubercles (Fig. 3, IV). The accessory orifice thus represented a remnant of the primitive atrio-ventricular canal. He pointed out that this theory would explain the fact that in many cases the accessory orifice was described as a hole in the anterior cusp of the valve.

In the present case the fibrous bridge appeared to be dividing what was otherwise a normal mitral valve. This fact would seem to favour the adhesion theory of Wimsatt and Hartmann as the mode of evolution of the double mitral valve in this instance.

Of considerable interest in this case is the fact that the patient was diagnosed in life as having mitral stenosis, on the basis of the apical mid-diastolic murmur heard by numerous observers over a period of at least four years. As noted above, a similar murmur was heard repeatedly in two other cases of duplication of the mitral valve and terminally in a third case. Thus, it seems evident that duplication of the mitral valve may occasionally mimic mitral stenosis. Furthermore, in Davies and Fisher's patient and in the present case, coarctation of the aorta was present in addition to the double mitral valve and in both an apical diastolic murmur was noted. Wood (1950) and Cleland et al. (in press) have drawn attention to the apical mid-diastolic murmur often heard in cases of coarctation of the aorta. In the series of Cleland et al., fifteen of the forty cases were noted to have an apical diastolic murmur prior to resection of the coarctation, and in nine of these the murmur was still present after operation. It is perhaps possible that duplication of the mitral valve might account for the murmur in some of the cases of this latter group, since the mitral anomaly and coarctation can occur in the same person.

In seeking the reason for the mitral murmur in this case, it is interesting to note that though the total circumference of the two orifices was $100 \mathrm{~mm}$. (the normal circumference of the mitral valve being 90 to $110 \mathrm{~mm}$.) the total area of the two openings $(415 \mathrm{sq} . \mathrm{mm}$.) was approximately one-half that of a normal mitral valve ( 800 sq. $\mathrm{mm}$.). Thus, there was present a form of congenital mitral stenosis. Other possible causes of this murmur could have been an eddying of blood about the fibrous bridge, or even a relative obstruction to blood flow by the anterior mitral cusp which was rendered semi-rigid by the calcium present.

A further point of interest in this case is the development of calcific aortic stenosis upon a congenital bicuspid aortic valve that is associated with coarctation of the aorta. Smith and Matthews (1955) have drawn attention to this occurrence and they concluded that the stenosis results from degenerative changes in the abnormal valve, which is subjected to high pressures as a result of the co-existing coarctation.

\section{Summary}

A 65-year-old woman, who presented with signs of congestive cardiac failure, had clinical evidence of both mitral and aortic stenosis. At necropsy she was discovered to have duplication of the mitral valve, a bicuspid aortic valve with superimposed calcareous stenosis, and mild coarctation of the aorta.

I am very grateful to Professor C. V. Harrison for his advice and help in the preparation of this report and to Doctor C. L. Cope for permission to study the case record. My thanks are also due to Miss R. Klein for the photographs and to Mr. F. G. Saunders for the diagrams.

\section{References}

Camisa, G. (1912). Cbl. allg. Path. path. Anat., 23, 1027.

Cleland, W. P., Counihan, T., Goodwin, J. F., and Steiner, R. (In press). Brit. med. J.

Cohn, I. (1897). Cbl. allg. Path. path. Anat., 8, 825.

Davies, J. N. P., and Fisher, J. A. (1934). Brit. Heart J., 5, 197.

Hartmann, B. (1937). Arch. Kreislaufforsch, 1, 286.

Matterstock, G. K. (1877). Dtsch. Arch. klin. Med., 19, 432.

Paul, F. (1930). Cbl. allg. Path. path. Anat., 50, 378.

Smith, D. E., and Matthews, M. B. (1955). Brit. Heart J., 17, 198.

Willis, R. A. (1952). The Spread of Tumours in the Human Body. Butterworths, London.

Wimsatt, W. A., and Lewis, F. T. (1948). Amer. J. Anat., 83, 67.

Wood, P. (1950). Brit. med. J., 2, 639. 